\title{
Influence of Process Parameters on Microstructure and Mechanical Properties in AA2024-T3 Friction Stir Welding
}

\author{
Pierpaolo Carlone $\cdot$ Gaetano S. Palazzo
}

Received: 6 February 2013/Revised: 14 May 2013/Accepted: 21 May 2013/Published online: 4 June 2013

(C) Springer Science+Business Media New York and ASM International 2013

\begin{abstract}
Material stirring and heat generation in friction stir welding processes induce significant microstructure and material properties alterations. Previous studies highlighted the relationship among microstructure, grain size, microhardness, and performance of the joint. In this context, an opportune definition of process parameters, in particular rotating and welding speed, is crucial to improve joint reliability. In this article, results provided by a numerical and experimental investigation on the influence of rotating and welding speed on microstructure, mechanical properties, and joint quality in AA2024-T3 friction stir welded butt joints are reported. Experimental data are presented and discussed considering numerically computed temperature and strain rate distributions, providing useful information for parameters setting. Processing window, i.e., parameters resulting in a successful material deposition, is also individuated.
\end{abstract}

Keywords Friction stir welding · Process model · Aluminum $\cdot$ Mechanical testing $\cdot$ Optical microscopy

\section{Introduction}

Medium to high strength aluminum alloys, such as $2 \mathrm{xxx}$, $6 \mathrm{xxx}$, and $7 \mathrm{xxx}$ series, are currently considered of great interest in the transport industries. For aeronautical applications, the precipitation hardenable AA2024 (Al-Cu) alloy is gaining considerable attention, in particular for the realization of barrier beams or fuselage panels.

P. Carlone $(\bowtie)$. G. S. Palazzo

Department of Industrial Engineering, University of Salerno,

Salerno, Italy

e-mail: pcarlone@unisa.it
In this context, remarkable research effort is focused on the application of the friction stir welding (FSW) process, as a suitable alternative to more traditional fusion welding processes, such as tungsten inert gas or laser welding. The aforementioned alloys are traditionally considered as nonweldable, due to the poor dendritic microstructure and high porosity in the weld zone, strongly reducing the mechanical behavior of the assembly. Furthermore, the reduction of production costs and weight and the increase of strength and damage tolerance with respect to riveted lap joints make FSW a very attractive process to the aerospace industry.

The FSW process, developed and patented by The Welding Institute (TWI) of Cambridge in 1991, is a solidstate welding process. Following the early successful applications in aluminum welding, FSW has been applied to other engineering materials, such as copper, steel, titanium, and metal matrix composites. Conceptually, the process is relatively simple: a non-consumable rotating tool, comprising a shoulder and a pin, is plunged between the adjoining edges of the parts to be welded and moved along the desired weld line. The combined rotation and translation of the tool locally increase the work piece temperature, due to heat generated by frictional effects and plastic deformation. The induced softening allows the processing material to flow around the pin, from the front (leading edge) to the rear (trailing edge) according to complex patterns, resulting in a solid-state weld [1]. Temperature increase and high strain rate deformation lead to the formation of microstructurally different zones: the nugget zone (NZ) in the center of the weld, surrounded by the thermo-mechanical-affected zone (TMAZ), and the heat-affected zone (HAZ). The NZ, also indicated as stir zone, is subjected to continuous dynamic recrystallization phenomena, resulting in significant grain refinement. Material flow in FSW is a topic of intense debate 
and a complete knowledge of the flow patterns during the FSW process has not been achieved yet. Most researchers support the similarity of the FSW with the extrusion process in the proximity of the pin, assisted also by a forging action of the shoulder. This assumption is also supported by the formation of periodic band structure, namely onion rings, observed in some materials and whose spacing is strictly related to process parameters [2-4]. Moreover, several specific defects are also imputable to inadequate material flow and deposition, mainly related to unsuitable process parameters [5].

At present, a deeper understanding of static strength as well as of fatigue behavior of FSWed assemblies is highly desired for a wider implementation of the technique in safety-critical components. In this sense, some results have already been presented in the inherent literature, concerning, for instance, to AA6082 and AA6061 [6], AA6063 [7], AA2024 [3, 4, 8-13], and dissimilar AA2024-AA7075 [14, 15] FSW joints. The slower crack propagation in FSWed material with respect to the base material has been highlighted and related to microstructure, microhardness, and residual stress. Specifically, Sutton et al. [3] performed microstructural, mechanical, and fracture analyses on AA2024-T351 friction stir welds, highlighting that the alternating hard particle-rich and hard particle-poor regions significantly influence the fracture process. A preferential crack path toward regions of high density of particles has been suggested [4]. Fratini et al. emphasized that crack growth behavior is affected by microstructure and hardness changes. Their experimental tests showed faster crack growth in the case of significant difference between welded zones and base material and opposite behavior in the case of hardness similarity [8]. Franchim et al. [9] characterized 1.6-mm-thick butt joints, welded at high feed rate $(700 \mathrm{~mm} / \mathrm{min})$. A joint efficiency of $98 \%$ in tensile strength and an equivalent stress intensity factor of 2 with respect to the base metal have been reported; however, the location of crack initialization is not specified within the article. Okada et al. [10] performed static and fatigue tests on 2-mm-thick FSW AA2024-T3 butt joints, considering also the influence of surface finish. Metallographic observations and microhardness measurements have been performed to predict probable crack nucleation sites. Fracture initiation was mainly related to tool marks, burrs, lack of penetration, and defects, such as kissing bonds and root flaws, in the aswelded specimens, while it was localized in the HAZ in the sound and finished specimen. A numerical finite element method (FEM)-dual boundary element method (DBEM) approach has been proposed in [11] to investigate the influence of residual stresses on fatigue crack growth in AA2024-T3 FSWed joints. Crack propagation was simulated in a DBEM environment, according to a two-parameter growth model, superimposing the process-induced stress field [12] to the stress field produced by a remote fatigue traction load. Despite the intriguing approach, microstructural and mechanical properties variations were not taken into account in residual stress computing, as well as in crack growth simulation. Vasudevan and coworkers [13] rationalized and discussed the combined influence of weld parameters and microstructural features on tensile properties and quasi-static fracture behavior in FSW of AA2024 in the T8 state. Khodir and Shibayanagi investigated the influence of the welding speed on quality, structure, and static mechanical properties in AA2024 and AA7075, respectively, in the T3 and T8 conditions [14]. Fracture was localized in correspondence with the hardness minimum of the weak alloy in sound joints and in the NZ in defected joints. The same conclusion has been highlighted in the study of da Silva et al. [15], which investigated the same joint configuration adopting three different rotating speeds and a constant value of the welding speed. Rodrigues et al. welded thin AA6016-T4 plates by means of different tool geometries and adopting process parameters corresponding to hot (HW) and cold (CW) welding [16]. It was shown that samples welded according to the HW parameters were characterized by better aspect of the crown, reduced hardness variations, and a relatively minor loss of ductility with respect to the base material. The influence of rotational speed on microstructure and mechanical properties in AA2024-T3 has been shown in [17], assuming constant welding speed in all tests. An increase of grain size and hardness in the NZ has been found with an increase in the rotating speed. The aforementioned variations have been related to fracture location point in tensile test.

Conclusions reported in most of the herein cited works converge on the suggestion of a strict relationship between joint performance and quality, to be related to the presence of defects, aspect of the crown, microstructure, and hardness distribution. With regard to AA2024-T3, the above features are significantly affected by dynamic recrystallization, dissolution, coarsening, and re-precipitation phenomena, whose kinetics are strongly influenced by thermal effect coupled to plastic deformation [18].

In this article, results provided by an experimental investigation on 4-mm-thick AA2024-T3 FSW butt joints are reported and discussed. Welded specimens have been subjected to macroscopic analysis to eventual defects, as well as to characterize the crown aspect. Metallographic observation has been carried on to evaluate grain size and microstructure in the welding zones, and microhardness profiles have been measured to study the effect of recrystallization and precipitates variation. Experimental data have been analyzed taking into account numerical results provided by a CFD Eulerian model of the process. The computational model has been solved using the ANSYS 
Table 1 AA2024-T3 properties

\begin{tabular}{|c|c|c|c|c|c|c|c|c|}
\hline Density $\rho\left(\mathrm{kg} / \mathrm{m}^{3}\right)$ & 2780 & $\cdots$ & $\cdots$ & $\ldots$ & $\cdots$ & $\cdots$ & $\cdots$ & $\cdots$ \\
\hline Conductivity $k(\mathrm{~W} / \mathrm{m} \mathrm{K})(T[\mathrm{~K}])$ & $121.8(298)$ & $134.4(373)$ & $151.2(473)$ & $172.2(573)$ & $176.4(673)$ & $\ldots$ & $\ldots$ & $\ldots$ \\
\hline Specific heat $c_{\mathrm{p}}(\mathrm{J} / \mathrm{kg} \mathrm{K})(T[\mathrm{~K}])$ & $921(298)$ & $921(373)$ & $1047(473)$ & $1130(573)$ & $1172(673)$ & $\ldots$ & $\ldots$ & $\ldots$ \\
\hline Yield stress $\sigma_{\mathrm{y}}\left(N / \mathrm{mm}^{2}\right)(T[\mathrm{~K}])$ & 345 (297) & $331(373)$ & $310(422)$ & $138(427)$ & $62(533)$ & $41(589)$ & $28(644)$ & $10(733)$ \\
\hline
\end{tabular}

CFX commercial package and validated by comparison with thermographic observation of the process.

\section{Materials and Methods}

\section{Experimental Procedure}

In this investigation, AA2024-T3 aluminum-rolled plates were joined by FSW. The nominal composition of the base material is as follows: $3.8-4.9 \mathrm{Cu}, 1.2-1.8 \mathrm{Mg}, 0.3-0.9 \mathrm{Mn}$, $0.5 \mathrm{Si}, 0.5 \mathrm{Fe}, 0.25 \mathrm{Zn}, 0.15 \mathrm{Ti}, 0.1 \mathrm{Cr}$, balance $\mathrm{Al}$ (wt\%). The material has been subjected to a solution heat treatment, followed by cold working and natural aging. Material physical and mechanical properties are listed in Table 1.

Plate dimensions are: $100 \times 30 \times 4 \mathrm{~mm}^{3}$ (length, width, and thickness). Friction stir welds have been executed normal to the rolling direction of the plates on a machining center (MCX 600 ECO). A steel clamping fixture has been opportunely realized, to fix the welding material according to the desired tilt angle. A full factorial design of experiments has been adopted, assuming, respectively, five and three levels for the rotating speed $\omega$ and feed rate $v$, as summarized in Table 2. Other process parameters, i.e., tilt angle $\Theta$, and pin penetration $p$ have been defined as $2^{\circ}$ and $0.2 \mathrm{~mm}$, according to literature indication and preliminary tests. The tool consisted of a $20 \mathrm{~mm}$ diameter shoulder with a conical pin, characterized by the following dimensions: height $3.80 \mathrm{~mm}$, major diameter $6.20 \mathrm{~mm}$, and cone angle $30^{\circ}$. The tool was made of AISI1040 quenched steel (56 HRC).

During the FSW process, surface temperature was acquired by means of an infrared thermo camera fixed on the machining center and focused on the leading edge of the weld, to provide experimental data for the validation of the implemented numerical model. Errors due to reflection of IR light emitted by the tool have been minimized by coating the monitored surfaces of adjoining plates (apart from the area interested by contact with the shoulder) with high temperature black paint. In addition, the uncoated weld crown has been shielded by means of a thin sheet fixed on the spindle at the back of the tool, as shown in Fig. 1(a). The emissivity coefficient of all surfaces (initial, black painted, and in correspondence of the weld crown) has been evaluated as a function of temperature and used to
Table 2 Experimental plan

\begin{tabular}{lll}
\hline Test & $v(\mathrm{~mm} / \mathrm{min})$ & $\omega(\mathrm{rpm})$ \\
\hline 1 & 35 & 800 \\
2 & 70 & \\
3 & 140 & 1000 \\
4 & 35 & \\
5 & 70 & 1200 \\
6 & 140 & \\
7 & 35 & 1400 \\
8 & 70 & \\
9 & 140 & 1600 \\
10 & 35 & \\
11 & 70 & \\
12 & 140 & \\
13 & 35 & \\
14 & 70 & \\
15 & 140 & \\
\hline
\end{tabular}

post process the image acquired by the thermo camera (Fig. 1b).

Welded samples have been subjected to visual inspection and qualitative analysis of crowns and roots, to detect evident the presence of flash or other undesired features. Metallographic observation, grain size evaluation, and microhardness measurements have been performed after 60 days of natural aging to ensure that a stable microstructure was obtained. Specimens have been sectioned by wire electro discharge machining (WEDM) in correspondence of the half-length and then polished and lapped on a rotating plate using abrasive disks (800, 1200, and 2500 grade), followed by a final polishing using a polycrystalline diamond suspension $(3 \mu \mathrm{m})$ on tissue disk. Keller's reagent $\left(1 \mathrm{ml} \mathrm{HF}, 1.5 \mathrm{ml} \mathrm{HCl}, 2.5 \mathrm{ml} \mathrm{HNO}_{3}\right.$, $95 \mathrm{ml}$ deionized $\mathrm{H}_{2} \mathrm{O}$ ) has been used for chemical etching (30 s at room temperature). The obtained samples have been subjected to macroscopic and microscopic analysis to individuate the presence of internal defect, such as tunnel defect, pin hole, and kissing bond. Vickers microhardness (HV0.1) has been measured in the mid thickness of the cut section, for a maximum distance of $20 \mathrm{~mm}$ in both the advancing and the retreating sides. Indentation and diagonal measurements have been performed along a programmed linear pattern, using the following parameters: 

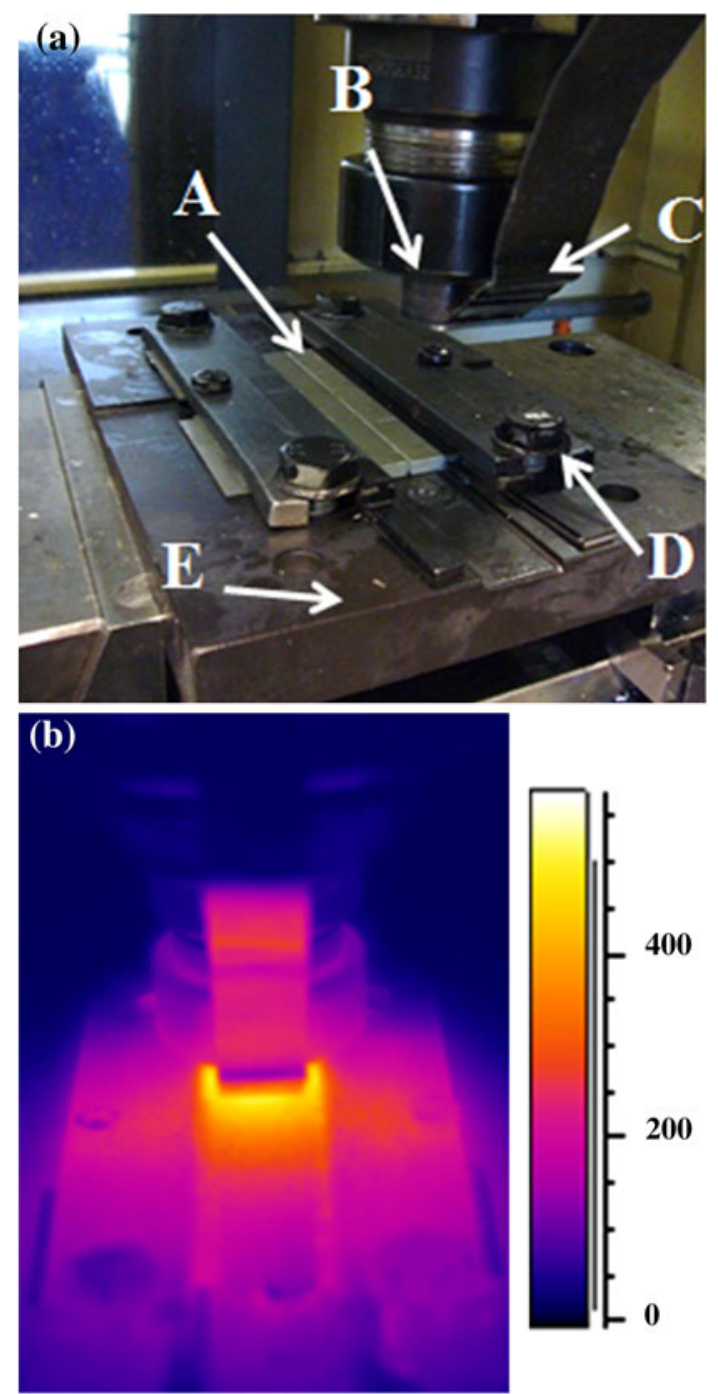

Fig. 1 (a) Experimental setup: adjoining plates $(A)$, tool (B), IR radiation shielding sheet $(C)$, clamping system $(D)$, inclined backing plate $(E)$; and $(\mathbf{b})$ thermographic image of the process

distance between two consecutive indentations $1 \mathrm{~mm}$, load 100 gf $(0.98 \mathrm{~N})$, loading time $15 \mathrm{~s}$, and indentation speed $60 \mu \mathrm{m} / \mathrm{s}$. Microstructural aspects have been investigated by conventional procedures, to observe welding zones (NZ, TMAZ, HAZ). Grain size measurements have been performed according to the ASTM E112 intercept method, considering four test lines ( $45^{\circ}$ angular spacing) for each analysis.

\section{Numerical Modeling and Validation}

Several computational FSW models, based on different approaches and numerical techniques, have been presented and discussed in the recent literatures [19-27]. A detailed discussion of FSW models and relative comparison is

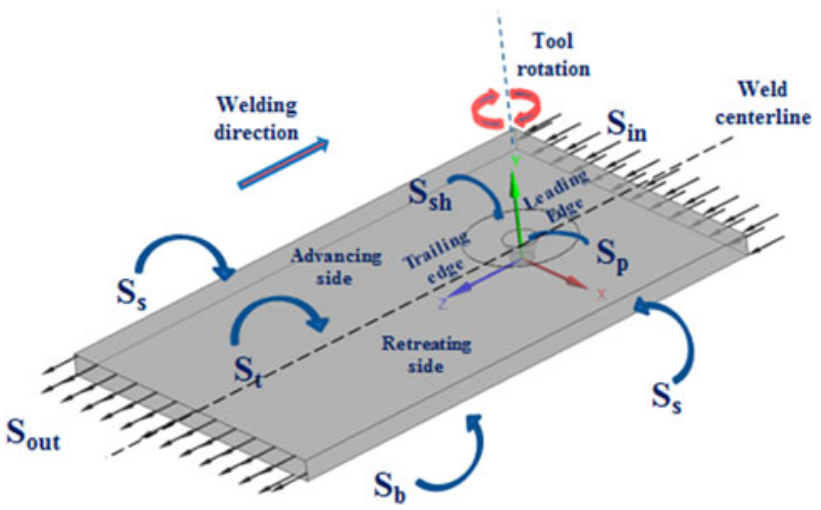

Fig. 2 Computational domain

beyond the aim of this article, therefore in what follows only the relevant aspects will be discussed. More information on heat generation and dissipation, contact conditions, metal flow, modeling advantages and disadvantages can be found in [28] and in the bibliography therein cited. Very briefly, it may be relevant to distinguish computational solid mechanics (CSM) or thermo-mechanical FE models [19, 20, 22, 27], from computational fluid dynamic (CFD) models [21, 23-26], which are based on the combined solution of continuity, momentum, and energy equations. Despite some limitations, mainly related to the simplistic assumption of negligible elastic stress far away from the tool and impossibility to capture residual stress, Eulerian CFD models are very suitable for flow and temperature field calculation and do not require remeshing. In this investigation, material flow and temperature distribution in FSW have been simulated by a CFD model in an Eulerian framework. The model has been implemented and solved using the commercial finite element package ANSYS CFX. The computational domain, shown in Fig. 2, has been limited to the workpiece, replacing the tool and the backing plate using opportune loads and boundary conditions. In particular, a constant velocity, equal and opposite to the welding speed $v$ has been imposed on the inlet $\left(S_{\text {in }}\right)$, bottom $\left(S_{\mathrm{b}}\right)$, and side $\left(S_{\mathrm{s}}\right)$ surfaces, while a free slip condition has been used for the top surface $\left(S_{\mathrm{t}}\right)$ not in contact with the tool. Finally, static pressure condition $(0 \mathrm{~Pa})$ has been applied on the outlet surface $\left(S_{\text {out }}\right)$. The processing material-tool interface has been defined considering a partial sticking/sliding contact state, regulated by the contact variable $\delta$, representing the sticking degree, i.e., the ratio between the angular velocity of the material $\omega_{\mathrm{m}}$ and of the tool surface $\omega[20,23,24,29-31]$. The contact variable has been defined as 0.65 , following literature indication for the same workpiece-tool materials [23, 30].

A constant temperature, equal to the room temperature $T_{\text {room }}$, has been imposed on the inlet surface $\left(S_{\text {in }}\right)$; convective boundary conditions, corresponding to calm air, 
have been applied on $S_{\mathrm{t}}$ and $S_{\mathrm{s}}$ surfaces, while the backing and clamping plates have been simulated by means of an effective heat transfer coefficient $\left(800 \mathrm{Wm}^{-2} \mathrm{~K}^{-1}\right)$. Heat generation, due to frictional effects and plastic work, has been modeled as a heat flux $(q)$ applied on shoulder and pin contact surfaces $\left(S_{\mathrm{sh}}, S_{\mathrm{p}}\right)$. Considering the Treska model $\left(\mu_{\mathrm{f}} p=m \tau_{\mathrm{y}}\right)$, after some manipulations, heat flux can be written as follows:

$q=\eta_{\mathrm{m}} \delta \omega r \tau_{\mathrm{y}}+(1-\delta) \eta_{\mathrm{w}} \omega r \mu_{\mathrm{f}} p$

$=\omega r \tau_{\mathrm{y}}\left(\eta_{\mathrm{m}} \delta+\eta_{\mathrm{w}} m(1-\delta)\right)$

being $r$ the radial distance from the tool axis, $\mu_{\mathrm{f}}$ the friction coefficient, $p$ the contact pressure, $\tau_{\mathrm{y}}$ the yielding shear stress $\left(\sigma_{\mathrm{y}} / \sqrt{3}\right), m$ the proportional coefficient, $\eta_{\mathrm{m}}$ the mechanical efficiency (amount of mechanical energy dissipated as heat), and $\eta_{\mathrm{w}}$ the frictional heat transferred to the workpiece. Coefficients $\eta_{\mathrm{m}}, \eta_{\mathrm{w}}$, and $m$ have been assumed equal to 0.9 , 0.7 , and 0.45 , respectively, considering reference values $[19,31]$. The processing material has been treated as a nonNewtonian, incompressible, viscoplastic fluid, in which behavior has been described by means of user-routines. The temperature and strain rate-dependent dynamic viscosity of the processing material has been assumed as follows [21]:

$\mu=\frac{\sigma_{\mathrm{e}}}{3 \dot{\varepsilon}_{\mathrm{e}}}$,

where $\dot{\varepsilon}_{\mathrm{e}}$ is the strain rate and $\sigma_{\mathrm{e}}$ is the flow stress. Considering the stress model early proposed by Sellars and Tegart [32] and later modified by Sheppard and Wright [33], it follows that

$\sigma_{\mathrm{e}}=\frac{1}{\alpha} \sinh ^{-1}\left(\left(\frac{Z}{A}\right)^{1 / n}\right)$,

where $A, \alpha$, and $n$ are material constants, and $Z$ is the Zener-Hollomon parameter, which is given as

$Z=\dot{\varepsilon}_{\mathrm{e}} \exp \left(\frac{Q}{R T}\right)$,

where $R$ is the gas constant, $Q$ the activation energy, and $T$ the material temperature. The parameters used are listed in Table 3.

Table 3 Viscosity parameters [36]

\begin{tabular}{lll}
\hline Parameter & Value & Unit \\
\hline$A$ & $3.25 \mathrm{E} 8$ & $1 / \mathrm{s}$ \\
$\alpha$ & 0.16 & $\mathrm{~N} / \mathrm{mm}^{2}$ \\
$n$ & 4.27 & - \\
$Q$ & 14,8880 & $\mathrm{~J} / \mathrm{mol}$ \\
$R$ & 8.314 & $\mathrm{~J} /(\mathrm{mol} \mathrm{K})$ \\
\hline
\end{tabular}

The implemented model has been validated by comparison with experimental temperature profiles provided by IR monitoring. Numerical and experimental temperature profiles along the centerline in the trailing edge of the weld are presented in Fig. 3, showing good agreement and evidencing the acceptable predictive capabilities of the implemented model.

\section{Results and Discussion}

Macroscopic and Cross-Sectional Observations

Macroscopic pictures of the weld crowns, as well as microscopic observations of the cross-section, are reported in Fig. 4. The crown appears relatively smooth and characterized by the presence of approximately circular marks at lower rotating speed. Differently, at higher $\omega$, a rougher surface has been obtained in correspondence of minor $v$, suggesting a major tendency to crack initiation. The above effect is related to the unstable equilibrium condition between the material hardening due to plastic deformation (promoting sliding) and softening caused by heat dissipation (increasing sticking), implicitly confirming the dependence of the contact state variable $\delta$ on the process parameters [19, 23, 24, 27].

Microscopic observations in Fig. 4 highlight a dominating influence of the $\omega$ on the continuity of the material inside the joint. Indeed, in all cases characterized by $\omega$ lower than or equal to $1200 \mathrm{rpm}$, several internal defects have been detected, mainly related to the formation of channel defects, localized in the lower region of the NZ toward the advancing side. Moreover, kissing bond defects have been observed in some of the aforementioned test cases. On the other hand, sound joints have been obtained assuming $\omega$ equal to 1400 and $1600 \mathrm{rpm}$, independently of

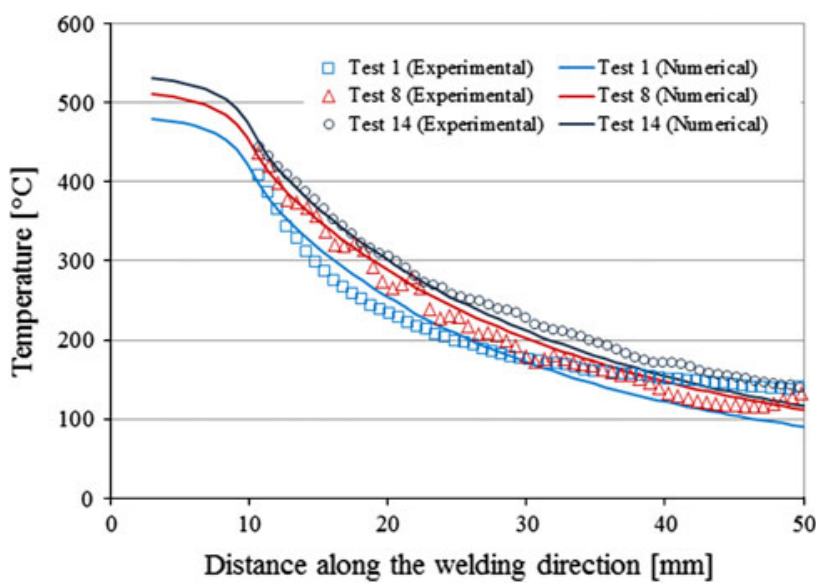

Fig. 3 Numerical and experimental temperature profiles along the weld centerline 
Fig. 4 Macroscopic detail of the weld crown (welding direction from the left to the right) and microscopic observation $(\times 50)$ of the transverse cross-section of the joints (advancing side on the left), according to different test conditions. Typical defects, such as channel defect $(A)$, kissing bond $(B)$, and pin hole $(C)$, have been evidenced

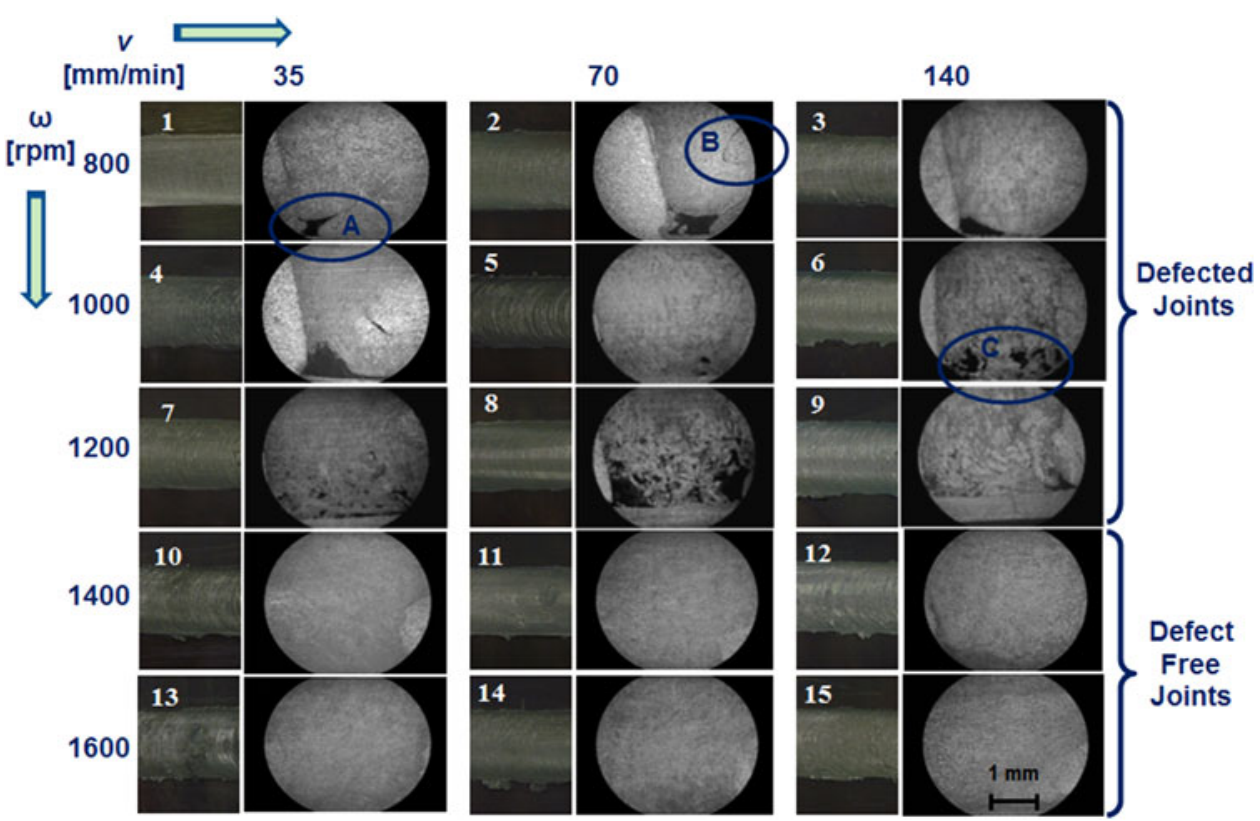

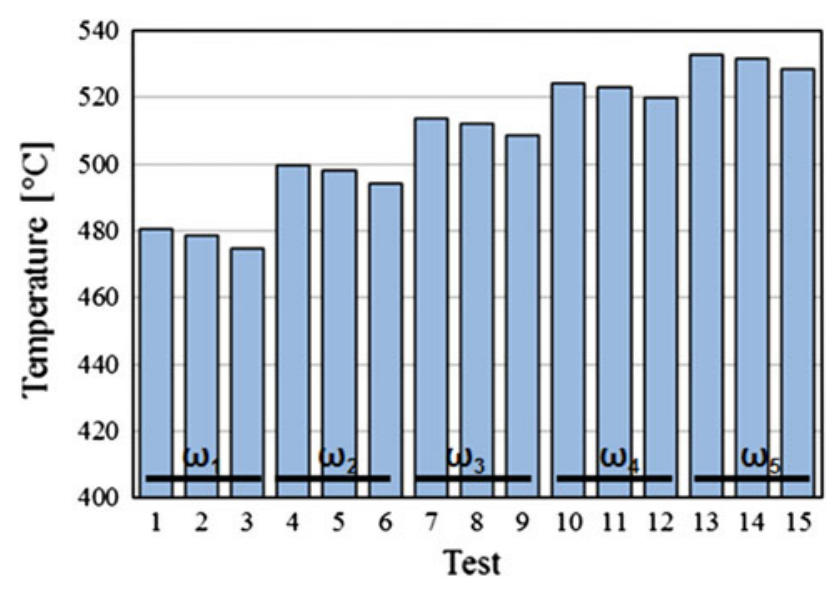

Fig. 5 Temperature peak in different welding conditions

$v$. The detected defects are typically related to insufficient material stirring at low temperature [5]. The potential presence of tunnel defects due to insufficient material deposition at the same location (lower advancing side) has been clearly indicated also in [20] and related to the low temperature near the root of the weld. The above consideration is also supported by numerical data reported in Figs. 5 and 6, showing, respectively, the temperature peak predicted according to the test conditions in Table 1, and the contour plot of the effective strain rate calculated at low (800 rpm) and high (1600 rpm) $\omega$.

As expected, the increase of $\omega$ implies a progressively major temperature peak due to the stronger heat generation (Fig. 5) and stirring effect (Fig. 6). On the other hand, temperature peak reduces at higher $v$, due to reduction of the heat dissipation in each material position. Simulated results show, in agreement with other reports [24, 29], that (a)

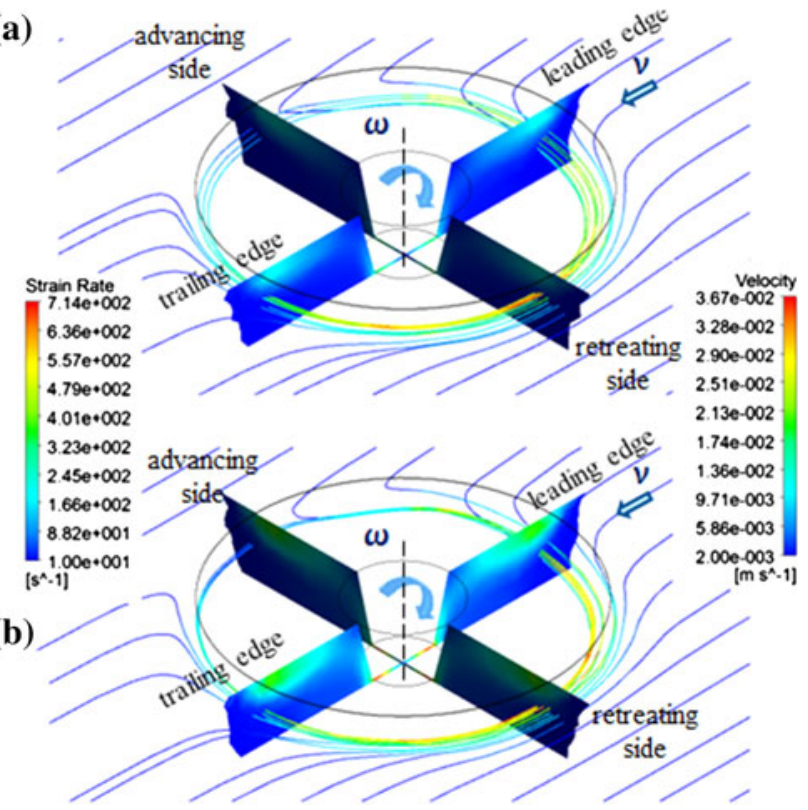

Fig. 6 Contour plot of the effective strain rate and streamlines showing the velocity history evaluated for (a) test $2(\omega=800 \mathrm{rpm}$, $v=70 \mathrm{~mm} / \mathrm{min})$ and $(\mathbf{b})$ test $14(\omega=1600 \mathrm{rpm}, v=70 \mathrm{~mm} / \mathrm{min})$. Strain rate and velocity color legends refer to both cases

the temperature peak increases less than proportionally with respect to $\omega$. Similar considerations can be formulated in terms of the linear heat input $H$, which, for the FSW process, can be written as

$H=\eta \frac{P}{v}=\eta \frac{M \omega}{v}$,

where $P$ is the power input and $M$ the applied torque. As clearly stated in Eq. 5, the amount of heat dissipated into 
the material per unit length increases with $\omega$, while the opposite dependence on $v$ is shown.

Moreover, it is worth noting that the nonlinear variation of the thermal peak with the rotating speed also implicitly suggests the dependence of the torque on this parameter. This partial compensating effect, played between $M$ and $\omega$, was already discussed in [34] on the basis of experimental observations. In the same work, less relevant variations of torque and power with $v$ were detected, resulting in an approximately linear relationship between the heat input and $v$, in agreement with the results obtained in this study.

Experimental observations suggested also a remarkable reduction of the processing window using unthreaded pin tools with respect to threaded ones. Indeed, previous studies reported the feasibility of the FSW process of AA2024 in the butt joint configuration at significantly lower rotating speed and assuming similar values for the welding speed. The realization of sound joints by FSW has been reported in [17], setting $\omega$ as 600, 800, 1000, and $1250 \mathrm{rpm}(v=50 \mathrm{~mm} / \mathrm{min})$, and in [26], assuming $\omega$ as $850 \mathrm{rpm}(v=65 \mathrm{~mm} / \mathrm{min})$. Reasonably, small differences related to the plate thickness ( $3 \mathrm{~mm}$ in [17] and $6 \mathrm{~mm}$ in [26]) with respect to this investigation cannot justify the discrepancy of the suitable $\omega$ values.

Microscopic Analysis: Microstructure and Microhardness Results

Metallographic observations of the cross-section showed the presence of the typical welding zones due to material heating and stirring (NZ, TMAZ, HAZ). The typical rolling microstructure was clearly visible in the unwelded base material. More specifically, elongated grains, characterized by mean grain size equal to $59.18 \mu \mathrm{m}$ and the presence of coarse precipitates, have been observed. Equiaxed grains of smaller size, ranging from $8.43 \mu \mathrm{m}$ in test $3-11.13 \mu \mathrm{m}$ in test 12, have been measured in the NZ of all welded samples, congruently with the influence of plastic deformation and heat input on recrystallized grain size. The variation of grain size with process parameters is graphically reported in Fig. 7, highlighting that increasing $\omega$ results in a relatively coarser microstructure. On the other hand, the opposite behavior is related to the increase of $v$.

This trend can be explained by considering that the grain size, resulting from the continuous dynamic recrystallization process, is inversely related to the Zener-Hollomon parameter [35], which, in turns, varies in a directly linear fashion with $\dot{\varepsilon}_{\mathrm{e}}$ and shows nonlinear inverse dependence on $T$ (Eq. 4). In other words, higher effective strain rate and lower temperature induce a finer grain. As a consequence, assuming the welding speed as constant, upon increasing the rotational speed, a relatively major heat flux is established between tool and work piece and higher temperature

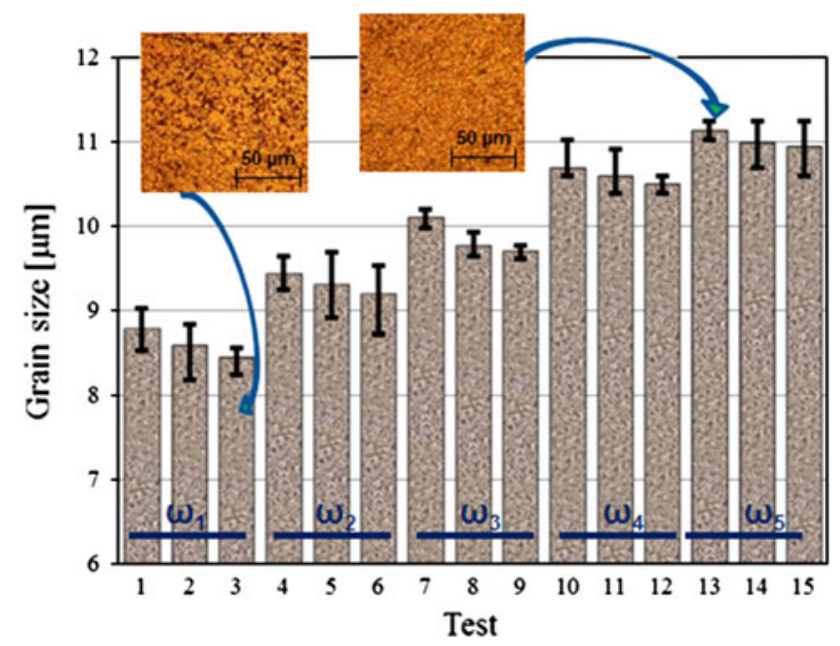

Fig. 7 Grain size in the nugget zone as a function of process parameters (error bars the maximum and minimum grain size measured in each specimen)

and strain rates are experienced by the processing material. On the other hand, keeping constant the rotational speed, the increase of the welding speed results in a (relatively less evident) reduction of temperature values, with negligible strain rate changes. In summary, regarding recrystallization phenomena in the NZ, a key role is played by the effective strain rate variations, mainly imputable to rotational speed changes.

A continuous variation of grain shape has been observed in the TMAZ, moving from the HAZ toward the NZ, with a clearly defined boundary separating the TMAZ and the NZ in the advancing side and a gradual transition in the retreating side, as in most of the herein cited reports. The extension of the TMAZ has been investigated following the criterion based on the critical dynamic viscosity value adopted in $[23,30]$. A critical value equal to 4E6 Pa s has been obtained matching numerical and experimental results (Fig. 8), in good agreement with data reported in the same references. As far as the influence of $\omega$ and $v$ on extension of the TMAZ is concerned, the results obtained here show negligible effects related to welding speed variations, while a more important role is played by the rotating speed, in accordance also with microhardness results discussed subsequently. The increase of $\omega$ implies also an external displacement of the TMAZ, as well as the HAZ boundaries. Indeed, the stronger stirring and heat generation lead to higher strain rate and temperature distributions in the transversal plane.

In the HAZ, no significant variation of grain size and shape has been found with respect to the parent material. The difference between the two microstructures was mainly related to the amount and aspect of precipitates, due to coarsening and dissolution phenomena, and it proved difficult to evidence using conventional optical techniques. 


\section{(a) Advancing side}

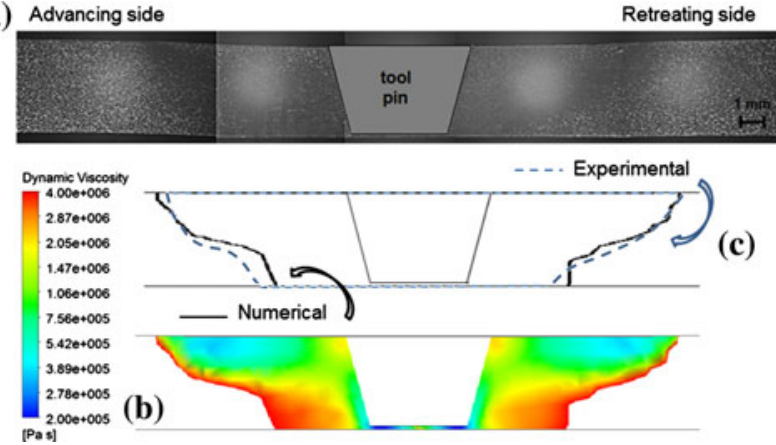

Fig. 8 Comparison between the experimental and numerical results: (a) micrographic observation of the weld cross-sectional region, (b) contour plot of the dynamic viscosity, and (c) comparison between numerically and experimentally evaluated TMAZ boundary

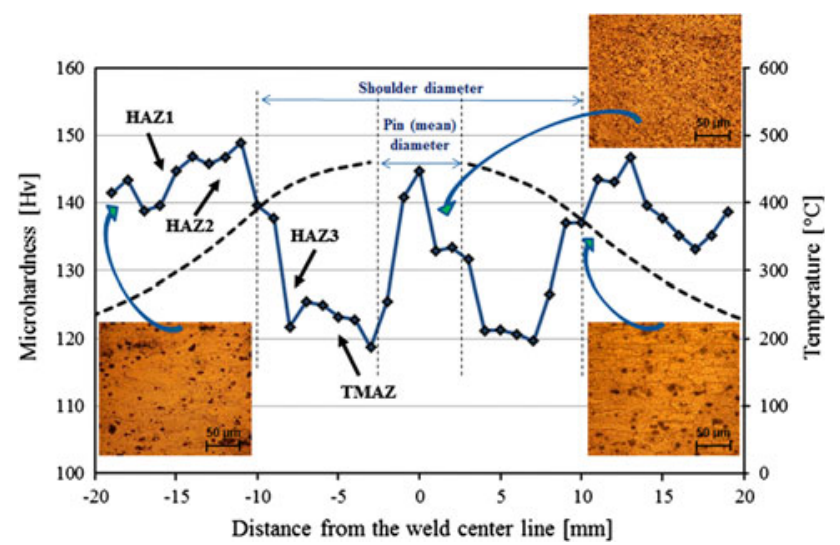

Fig. 9 Microhardness (solid line) and temperature (dashed line) profiles in the half thickness of the welded specimen (test 3, 60-day natural aging)

Figure 9 shows a microhardness profile measured along a test line at half thickness of the cross-section, showing also microscopic observations of different welding zones. On the same plot, the numerically computed temperature profile, along the same line, is superimposed. The HV trend can be explained considering the coupled effect of plastic deformation and thermal cycle on precipitation kinetics, well detailed in [18], and is in very good agreement with direct observation reported in the same article.

A HV peak has been measured in correspondence of the $\mathrm{NZ}$, due to grain size reduction (for a minor extent) and (mainly) to hard precipitate formation, in agreement with other observations [17]. Indeed, the elevated temperature experienced during the process (see also Fig. 5) forces several precipitates (Guinier-Preston-Bagaryatsky or GPB zones) to dissolve or coalesce. The microhardness reduction with respect to parent material, observed in most cases, has been related to substitution of previous hard precipitates by $S^{\prime}(S)$ phase. Furthermore, several solute precipitates re-precipitate during naturally aging, resulting in a
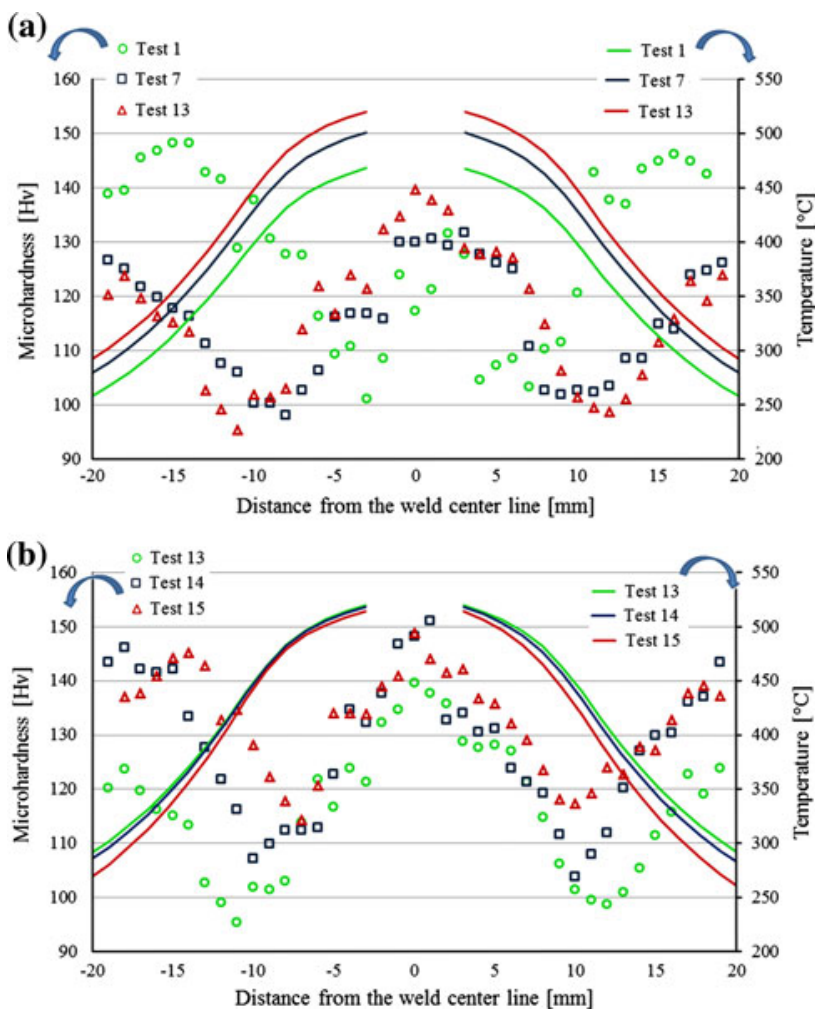

Fig. 10 Comparison of microhardness profiles in the half thickness of the welded specimen (60-day natural aging): (a) at different rotating speed $(v=70 \mathrm{~mm} / \mathrm{min}, \omega=800,1200$, and $1600 \mathrm{rpm})$; (b) at different welding speed $(v=35,70$, and $140 \mathrm{~mm} / \mathrm{min}$, $\omega=1600 \mathrm{rpm})$. Continuous lines The numerically computed temperature profiles along the measurement line

certain hardness recovery. In some cases, corresponding to higher temperature, the thermal history allows a major nucleation of harder GPB zones on aging, leading to HV values equal or even higher with respect to the parent material (Figs. 10, 11). A progressive microhardness reduction has been detected in the TMAZ on both sides of the NZ, with the absolute minimum localized in most cases into the advancing side of the weld. This trend is imputable to $S^{\prime}(S)$ coarsening and GPB zones dissolution. Moreover, processing temperature resulted relatively lower and no significant hardness recovery after naturally aging was detected in this zone.

Previous studies highlighted that, for the considered material, the separation boundary between HAZ and BM is not easy to evidence using conventional optical microscopy. However, some indications can be derived considering precipitation kinetics and the influence of precipitates on microhardness distribution. A sharp HV increase has been measured in correspondence of the transition from the TMAZ to the HAZ. Moreover, a variable HV trend in the HAZ has been found, confirming the definition of three different sub-zones, namely HAZ1, HAZ2, and HAZ3, suggested in [18]. In particular, the HV increase in HAZ3 


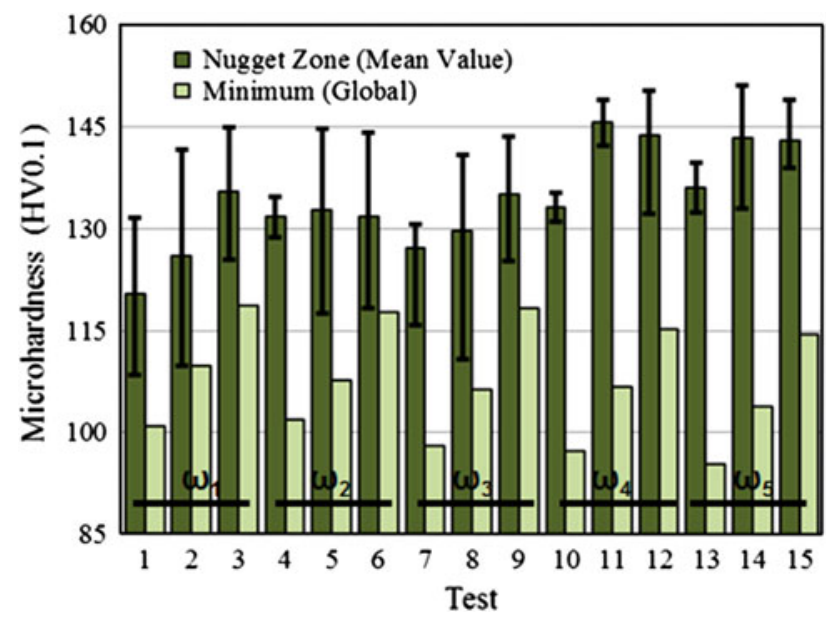

Fig. 11 Microhardness results at different processing conditions. Dark bars The mean HV value in the NZ (error bars maximum and minimum HV in the same zone), light bars the minimum HV value measured along the test line

with respect to the TMAZ (but with lower values if compared with the parent material) is related to the weaker coarsening of $S^{\prime}(S)$ phase at elevated temperature (about $370{ }^{\circ} \mathrm{C}$ ). In the adjacent zone (HAZ2), subjected to a temperature range centered on about $300{ }^{\circ} \mathrm{C}$, the strong precipitation of fine $S^{\prime}(S)$ phase resulted in a $\mathrm{HV}$ peak even major than the BM hardness. Finally, material in HAZ1 is characterized by a further but less evident $\mathrm{HV}$ reduction, until the initial value (146 HV) is recovered. In this zone, the temperature experienced during the process (slightly higher than $200-250{ }^{\circ} \mathrm{C}$ ) induced the dissolution of GPB zones without precipitation of coarse $S^{\prime}(S)$ phase.

Figures 10 and 11 graphically represent the influence of processing parameters on microhardness distribution. In particular, Fig. 10 shows some experimental $\mathrm{HV}$ and numerical temperature profiles as a function of $\omega$ and $v$, while Fig. 11 summarizes relevant data from all test cases. As can be seen, the previously discussed HV trend has been found in all welded specimens, relative to the investigated zone. Experimental data illustrate that mean and maximum value of $\mathrm{HV}$ in the NZ increase slightly with $\omega$, in agreement with the above interpretation. In addition, as $\omega$ increases, an enlargement of the $\mathrm{W}$-shaped profile described by HV is clearly visible, in agreement with the above discussion regarding the HAZs extension. The influence of $v$ can be explained by considering that it directly affects the local thermal cycle, i.e., the heating and cooling rates. Taking into account that a faster heating reduces the time for precipitate coarsening, and a faster cooling increases the amount of supersaturated solute available to re-precipitate on aging, the relatively higher peak in the NZ at major $v$, as well as the lower values in the TMAZ at minor $v$ are to be expected.

\section{Conclusions}

In this article, results provided by a numerical and experimental investigation on AA2024-T3 FSW, in the butt joint configuration and using an unthreaded conical tool, have been reported and discussed. In particular, attention has been focused on the influence of rotating and welding speed on joint quality, microstructure and mechanical properties, adopting a full factorial design of experiments. Taking into account the reported results, the following conclusions can be highlighted:

- a key role is played by the rotating speed to obtain sound joints. In particular, adequate flow conditions and material deposition, i.e., resulting into the absence of defects, have been induced for $\omega$ higher than $1200 \mathrm{rpm}$; at lower $\omega$ several defects (channel defects and kissing bond) have been detected in the advancing side of the NZ. A larger processing window has been reported in the cited literature using threaded pin tools. Moreover, in sound joints, the crown aspect worse increasing $\omega$ and assuming low $v$, implicitly suggesting a major tendency to crack initiation;

- grain size in the recrystallization area is affected by both processing parameters; smaller grain size has been measured for low $\omega$ and high $v$ and vice versa;

- microhardness profiles, measured after naturally aging, show a $\mathrm{W}$-shape with a peak in the NZ and minimum value between the TMAZ and the HAZ. Relatively wider-affected zones are induced increasing $\omega$, while $v$ significantly affects the maximum and minimum $\mathrm{HV}$ values. Moreover, HV profiles confirmed precipitation kinetics analysis proposed in [18].

\section{References}

1. R.S. Mishra, Z.Y. Ma, Friction stir welding and processing. Mater. Sci. Eng. R 50, 1-78 (2005)

2. H.N.B. Schmidt, T.L. Dickerson, J.H. Hattel, Material flow in butt friction stir welds in AA2024-T3. Acta Mater. 54, 1199-1209 (2006)

3. M.A. Sutton, B. Yang, A.P. Reynolds, R. Taylor, Microstructural studies of friction stir welds in 2024-T3 aluminum. Mater. Sci. Eng. A Struct. 323, 160-166 (2002)

4. B. Yang, J. Yan, M.A. Sutton, A.P. Reynolds, Banded microstructure in AA2024-T351 and AA2524-T351 aluminum friction stir welds Part I. Metallurgical studies. Mater. Sci. Eng. A Struct. 364, 55-65 (2004)

5. H.-B. Chen, K. Yan, T. Lin, S.-B. Chen, C.-Y. Jiang, Y. Zhao, The investigation of typical welding defects for 5456 aluminum alloy friction stir welds. Mater. Sci. Eng. A Struct. 433, 64-69 (2006)

6. P.M.G.P. Moreira, A.M.P. de Jesus, A.S. Ribeiro, P.M.S.T. de Castro, Fatigue crack growth in friction stir welds of 6082-T6 and 
6061-T6 aluminium alloys: a comparison. Theor. Appl. Fract. Mech. 50, 81-91 (2008)

7. P.M.G.P. Moreira, F.M.F. de Oliveira, P.M.S.T. de Castro, Fatigue behaviour of notched specimens of friction stir welded aluminium alloy 6063-T6. J. Mater. Process. Technol. 207, 283-292 (2008)

8. L. Fratini, S. Pasta, A.P. Reynolds, Fatigue crack growth in 2024-T351 friction stir welded joints: longitudinal residual stress and microstructural effects. Int. J. Fatigue 31, 495-500 (2009)

9. A.S. Franchim, F.F. Fernandez, D.N. Travessa, Microstructural aspects and mechanical properties of friction stir welded AA2024-T3 aluminium alloy sheet. Mater. Des. 32, 4684-4688 (2011)

10. T. Okada, M. Suzuki, H. Miyake, T. Nakamura, S. Machida, M. Asakawa, Evaluation of crack nucleation site and mechanical properties for friction stir welded butt joint in 2024-T3 aluminum alloy. Int. J. Adv. Manuf. Technol. 50, 127-135 (2010)

11. P. Carlone, R.G. Citarella, M. Lepore, G.S. Palazzo, Numerical crack growth analysis in AA2024-T3 friction stir welded butt joints. in Proceedings of the 8th International Conference on Engineering Computational Technology, September 4-7 (Dubrovnik, 2012), pp. 1-10. doi:10.4203/ccp.100.91

12. P. Carlone, G.S. Palazzo, Experimental analysis of the influence of process parameters on residual stress in AA2024-T3 friction stir welds. Key Eng. Mater. 504-506, 753-758 (2012)

13. T.S. Srivatsan, S. Vasudevan, L. Park, The tensile deformation and fracture behavior of friction stir welded aluminum alloy 2024. Mater. Sci. Eng. A Struct. 466, 235-245 (2007)

14. S.A. Khodir, T. Shibayanagi, Friction stir welding of dissimilar AA2024 and AA7075 aluminum alloys. Mater. Sci. Eng. B Adv. 148, 82-87 (2008)

15. A.A.M. da Silva, E. Arruti, G. Janeiro, E. Aldanondo, P. Alvarez, A. Echeverria, Material flow and mechanical behaviour of dissimilar AA2024-T3 and AA7075-T6 aluminium alloys friction stir welds. Mater. Des. 32, 2021-2027 (2011)

16. D.M. Rodrigues, A. Loureiro, C. Leitao, R.M. Leal, B.M. Chaparro, P. Vilaça, Influence of friction stir welding parameters on the microstructural and mechanical properties of AA 6016-T4 thin welds. Mater. Des. 30, 1913-1921 (2009)

17. S.A. Khodir, T. Shibayanagi, M. Naka, Microstructure and mechanical properties of friction stir welded AA2024-T3 aluminum alloy. Mater. Trans. 47(1), 185-193 (2006)

18. C. Genevois, D. Fabrègue, A. Deschamps, W.J. Poole, On the coupling between precipitation and plastic deformation in relation with friction stir welding of AA2024 T3 aluminium alloy. Mater. Sci. Eng. A Struct. 441, 39-48 (2006)

19. D. Jacquin, B. de Meester, A. Simar, D. Deloison, F. Montheillet, C. Desrayaud, A simple Eulerian thermomechanical modeling of friction stir welding. J. Mater. Process. Technol. 211, 57-65 (2011)

20. H. Schmidt, J. Hattel, A local model for the thermomechanical conditions in friction stir welding. Model. Simul. Mater. Sci. Eng. 13, 77-93 (2005)
21. P.A. Colegrove, H.R. Shercliff, 3-Dimensional CFD modelling of flow round a threaded friction stir welding tool profile. J. Mater. Process. Technol. 169, 320-327 (2005)

22. Z. Zhang, J.T. Chen, Z.W. Zhang, H.W. Zhang, Coupled thermomechanical model based comparison of friction stir welding processes of AA2024-T3 in different thicknesses. J. Mater. Sci. 46, 5815-5821 (2011)

23. H. Atharifar, D. Lin, R. Kovacevic, Numerical and experimental investigations on the loads carried by the tool during friction stir welding. J. Mater. Eng. Perform. 18, 339-350 (2009)

24. H.B. Schmidt, J.H. Hattel, Thermal and material flow modelling of friction stir welding using Comsol, in Proceedings of the COMSOL Conference 2008 Hannover

25. S.Z. Aljoaba, I.S. Jawahir, O.W. Dillon Jr, M.H. Ali, M.K. Khraisheh, Modelling of friction stir processing using 3D CFD analysis. Int. J. Mater. Form. 2(1), 315-318 (2009)

26. C.-S. Wu, W.-B. Zhang, L. Shi, M.-A. Chen, Visualization and simulation of plastic material flow in friction stir welding of 2024 aluminium alloy plates. Trans. Nonferr. Metal. Soc. 22, 1445-1451 (2012)

27. R.K. Uyyuru, S.V. Kailas, Numerical analysis of friction stir welding process. J. Mater. Eng. Perform. 15, 505-518 (2006)

28. D.M. Neto, P. Neto, Numerical modeling of friction stir welding process: a literature review, Int. J. Adv. Manuf. Technol. (2012). doi:10.1007/s00170-012-4154-8

29. J.H. Hattel, H.N.B. Schmidt, C. Tutum, Thermomechanical modelling of friction stir welding, in Proceedings of the 8th International Conference on Trends in Welding Research, June 1-6, 2008 (Pine Mountain, USA), pp. 1-10

30. R. Nandan, G.G. Roy, T. Debroy, Numerical simulation of threedimensional heat transfer and plastic flow during friction stir welding. Metall. Mater. Trans. A 37, 1247-1259 (2006)

31. G. Buffa, J. Hua, R. Shivpuri, L. Fratini, A continuum based fem model for friction stir welding-model development. Mater. Sci. Eng. A Struct. 419, 389-396 (2006)

32. C.M. Sellars, W.J.McG Tegart, Hot workability. Int. Metall. Rev. 17(1), 1-24 (1972)

33. T. Sheppard, D.S. Wright, Determination of flow stress: Part I-constitutive equation for aluminum alloys at elevated temperatures. Met. Technol. 6, 215-223 (1979)

34. A. Arora, R. Nandan, A.P. Reynolds, T. DebRoy, Torque, power requirement and stir zone geometry in friction stir welding through modeling and experiments. Scr. Mater. 60, 13-16 (2009)

35. P. Carlone, G.S. Palazzo, A numerical and experimental analysis of microstructural aspects in AA2024-T3 friction stir welding. Key Eng. Mater. 554-557, 1022-1030 (2013)

36. I. Flitta, T. Sheppard, Material flow during the extrusion of simple and complex cross-sections using FEM. Mater. Sci. Technol. 21(6), 648-656 (2005) 